\title{
A SYSTEMATIC ALCHEMI STUDY OF Fe-DOPED NiAI ALLOYS
}

\author{
I.M. Anderson,* A.J. Duncan, $\uparrow$ and J. Bentley* \\ *Metals \& Ceramics Division, Oak Ridge National Laboratory, P.O. Box 2008, Oak Ridge, TN 37831 \\ $\dagger$ Department of Materials Science \& Engineering, University of Florida, Gainesville, FL 32611
}

ALCHEMI site-occupation studies of alloying additions to ordered aluminide intermetallic alloys have been performed with varying degrees of success, depending on the ionization delocalization correction procedure applied to the data. 1,2 Most published studies have been applied to just one or two alloys in order to ascertain qualitatively the site-preference of the alloying element. However, quantitative siteoccupancies can be extracted from carefully performed ALCHEMI experiments as long as the data are properly treated for ionization delocalization and anti-site occupancies. 3,4 Systematic studies can therefore yield the dependence of site-occupancies in alloys on independent thermodynamic variables. The purpose of the present study is to examine the variation in the site-occupancy of $\mathrm{Fe}$ in B2-ordered $\mathrm{NiAl}$ as a function of solute concentration and alloy stoichiometry.

Twelve different alloys were prepared for this study with stoichiometries $\mathrm{Ni}_{50-\mathrm{x}} \mathrm{Al}_{50} \mathrm{Fe}_{\mathrm{x}}$ (Ni-deficient),

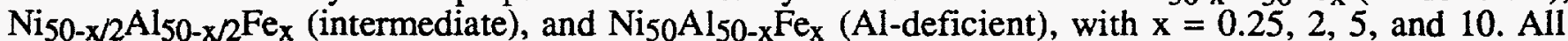
alloys were homogenized at $1300^{\circ} \mathrm{C}$ for $5 \mathrm{~h}$, step-cooled to room temperature, then annealed at $800^{\circ} \mathrm{C}$ for $72 \mathrm{~h}$ and water quenched. Three-millimeter discs were spark-cut from slices of each alloy and thinned by electrojet polishing. Energy-dispersive x-ray (EDX) spectra were acquired with a Philips CM12 operated at $120 \mathrm{kV}$ and equipped with $\mathrm{LaB}_{6}$ filament, an EDAX 9900 spectrometer and superUTW $\mathrm{Si}(\mathrm{Li})$ detector. Experiments were performed with a beam divergence semi-angle of 3 milliradians, which is approximately one-quarter of the Bragg angle of a $\{200\}$ reflection. Spectra were acquired near $\langle 014\rangle$ beam direction at $\sim 10$ distinct $\{200\}$ excitations between the symmetry and the $\{600\}$ Bragg orientations. Diffracting conditions were chosen to minimize the excitation of nonsystematic reflections and the beam current was monitored and held at a constant value.

Data analysis was performed by correlating the characteristic $\mathrm{x}$-ray intensities of the $\mathrm{Fe}$ alloying element with those of the $\mathrm{Ni}$ and $\mathrm{Al}$ host elements with linear regression analysis, as discussed elsewhere. ${ }^{4}$ Ionization delocalization correction was performed with factors extracted from data acquired at a [110\} systematics orientation. ${ }^{5}$ Because of the low counting statistics of the $0.25 \%-\mathrm{Fe}$-containing alloys, the delocalization-corrected site distributions $\chi_{\mathrm{kj}}$ of these alloys were normalized so that $\Sigma=\chi_{\mathrm{FeNi}}+\chi_{\mathrm{FeAl}}$ $=1$. This procedure was deemed valid because the average (before normalization) of the $\Sigma$ values among the alloys was unity, so that systematic error should not be introduced. This procedure effectively utilizes the counts from all spectra, rather than just one spectrum, to determine the $\mathrm{k}$-factor for the dilute Fe-impurity. Two independent ALCHEMI analyses were performed for each of the $0.25 \%$-Fecontaining alloys because of the large statistical error of these analyses.

The results of these analyses are shown in Fig. 1. Here, the fraction of $\mathrm{Fe}$ on the 'Ni'-site, PFe'Ni', is plotted as a function of $\mathrm{Fe}$-concentration, $\mathrm{x}$. Different symbols are used for the three different Ni-Al stoichiometries, as indicated. The results of the two analyses from each $0.25 \%$-Fe-containing alloy are plotted separated by the width of the symbol on either side of $x=0.25$, for clarity. The site-occupancies extracted from the two analyses of each $0.25 \%$-Fe-containing alloy agree to well within one standard deviation. This agreement shows that the normalization procedure enhances the precision of the measurement, as expected. The good separation among the data from alloys of the three stoichiometries clearly shows that the site occupancy of iron depends upon the relative concentrations of the $\mathrm{Ni}$ and $\mathrm{Al}$ host elements. However, a preference for the 'Ni'-site is clearly indicated: more than half of the iron occupies the 'Ni'-site in all of the intermediate alloys, and the iron occupies a higher fraction of 'Ni'-sites in the Ni-deficient alloys than it does 'Al'-sites in the Al-deficient alloys. Definite trends in the dependence of site-occupancy on solute concentration are apparent for each alloy stoichiometry. The site-occupancies in alloys of intermediate stoichiometry are relatively independent of $\mathrm{Fe}$-concentration. Conversely, in the Al-deficient alloys the fraction of Fe occupying ' $\mathrm{Ni}$ '-sites decreases with increasing

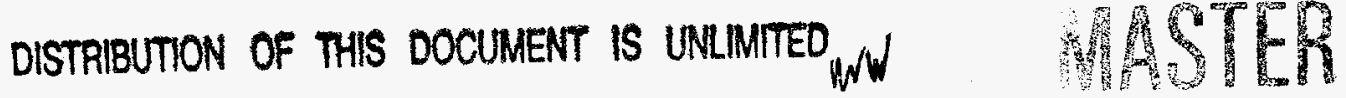


solute concentration. In the $\mathrm{Ni}$-deficient alloys, the 'Ni'-site-occupancy of $\mathrm{Fe}$ at solute concentrations $\geq 5 \%$ is enhanced $(\sim 95 \%)$ relative to that $(\sim 90 \%)$ for concentrations $\leq 2 \%$.

The similarity in the site-occupancies of the dilute $0.25 \%$-Fe-containing alloys of intermediate and 'Al'deficient stoichiometries is noteworthy. Because of the difficulty in assuring alloy stoichiometry at such low solute levels, the increase of $\mathrm{pFe} \mathrm{Ni}^{\prime}$ in the Al-deficient alloy relative to the members of this family having higher solute levels is suspicious in the absence of intermediate data points. However, the three $0.25 \%$ alloys were arc-melted from the same ingot of stoichiometric $\mathrm{NiAl}$, with appropriate additions of the solute and host elements. The site-occupancies of the dilute alloys of Ni-deficient and intermediate stoichiometries are consistent with those of higher solute levels in their respective families, hence it is unlikely that the change in site-occupancy of the Al-deficient alloy results entirely from a systematic error in stoichiometry. Moreover, the constitutional point-defect concentration needed to compensate the relatively high ' $\mathrm{Ni}$ '-site occupancy at the $0.25 \%$ solute level is smaller than that in any of the three $2 \%$ Fe-containing alloys. A tendency of the site-occupancy to approach a constant low-concentration value, as indicated by the site-occupancies of the alloys of intermediate stoichiometry, is plausible. ${ }^{6}$

\section{References}

1. J. Bentley, Proc. Ann. EMSA Meeting 44(1986)704.

2. P.R. Monroe and I. Baker, J. Mat. Res. 7(1992) 2119.

3. M.G. Walls, Microsc. Microanal. Microstruct. 3(1992)443.

4. I.M. Anderson and J. Bentley, Proc. 13 ${ }^{\text {th }}$ ICEM: Electron Microscopy 1994 1(1994)609.

5. I.M. Anderson and J. Bentley, these proceedings (1995).

6. This research is supported by the Division of Materials Sciences and by the Assistant Secretary for Energy Efficiency and Renewable Energy, Office of Industrial Technologies, Advanced Industrial Materials Program, U.S. Department of Energy, under contract DE-AC05-84OR21400 with Martin Marietta Energy Systems, Inc. This work is also partially supported by an appointment (IMA) to the Oak Ridge National Laboratory (ORNL) Postdoctoral Research Associates Program, which is administered jointly by the Oak Ridge Institute for Science and Education and ORNL.

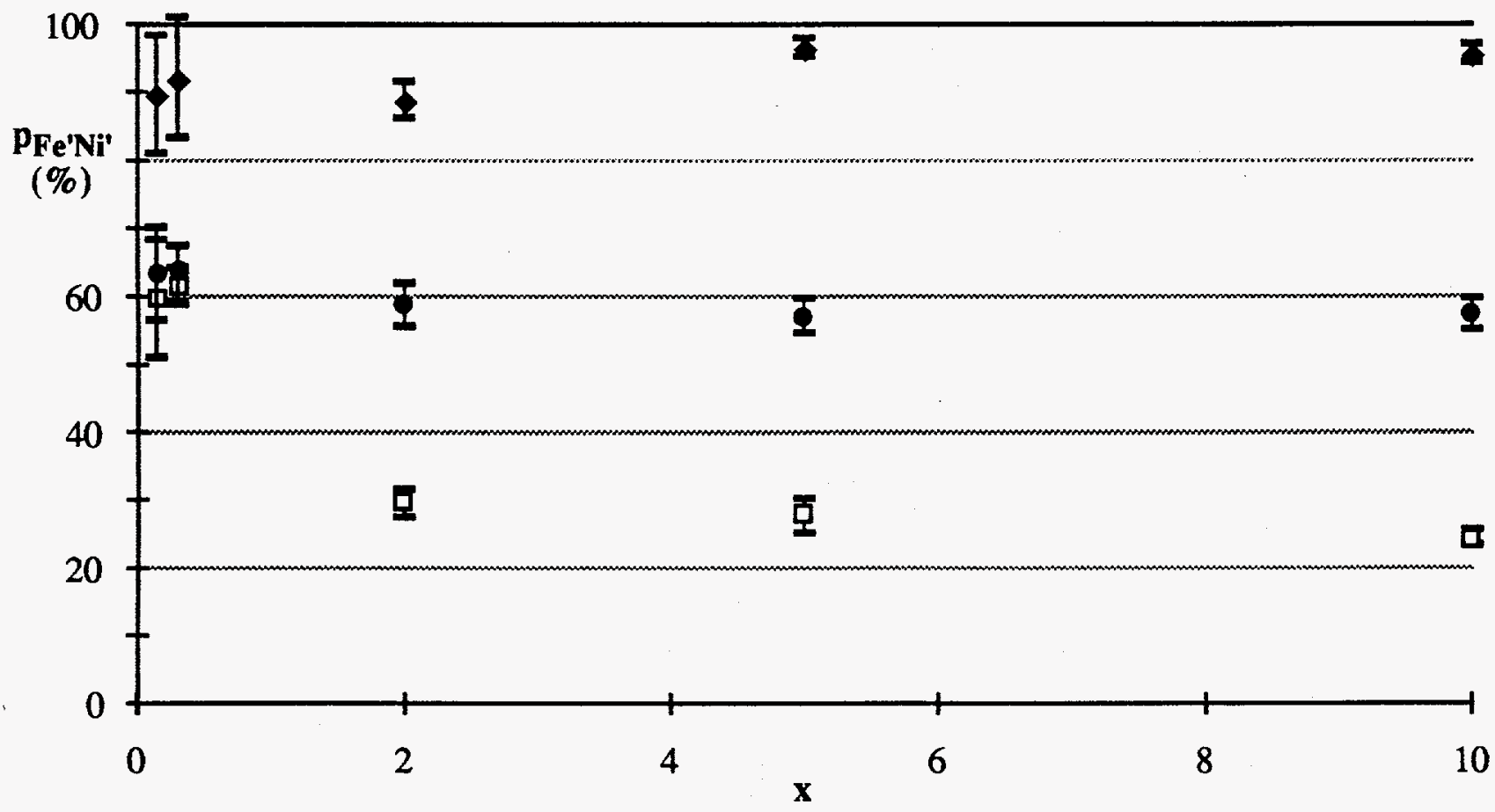

FIG. 1. Fraction of Fe occupying 'Ni'-sites, pFe'Ni', in $\mathrm{NiAl}$ alloys as a function of at.\% $\mathrm{Fe}$, $\mathrm{x}$, for $\mathrm{Ni}$ deficient (diamonds), Al-deficient (squares), and intermediate (circles) $\mathrm{Ni}$-Al stoichiometries. 


\section{DISCLAIMER}

This report was prepared as an account of work sponsored by an agency of the United States Government. Neither the United States Government nor any agency thereof, nor any of their employees, makes any warranty, express or implied, or assumes any legal liability or responsibility for the accuracy, completeness, or usefulness of any information, apparatus, product, or process disclosed, or represents that its use would not infringe privately owned rights. Reference herein to any specific commercial product, process, or service by trade name, trademark, manufacturer, or otherwise does not necessarily constitute or imply its endorsement, recommendation, or favoring by the United States Government or any agency thereof. The views and opinions of authors expressed herein do not necessarily state or reflect those of the United States Government or any agency thereof. 


\section{DISCLAIMER}

Portions of this document may be illegible in electronic image products. Images are produced from the best available original document. 